\title{
Da dieta à reeducação alimentar: algumas notas sobre o comer contemporâneo a partir dos programas de emagrecimento na Internet
}

\section{| ${ }^{1}$ Ligia Amparo da Silva Santos |}

Resumo: O texto tem como objetivo refletir sobre o comer contemporâneo, partindo de um estudo sobre estratégias educativas utilizadas pelos programas de emagrecimento oferecidos via Internet, o qual detecta uma possível transição da ideia de fazer dieta para a de reeducação alimentar. Identifica que a principal mensagem preconizada pelos sites é "emagrecer, de uma forma saudável, equilibrada e natural, através da adoção de novos hábitos alimentares, em que se pode comer de tudo, sem privações e sacrifícios, com prazer, sem privar-se da vida social”, e que os mesmos utilizam o conjunto das estratégias combinando três elementos fundamentais: o estímulo e motivação com um forte apoio psicológico e de marketing; "comer de tudo" com a promessa de não abrir mão do prazer e o "sem passar fome" como controlar o apetite. O texto ainda discute aspectos sobre a ressignificação do comer, da comida e dos alimentos que passam pela construção de uma nova distinção alimentar. Finaliza destacando que o momento atual parece construir bases que sustentam a disciplina alimentar contemporânea. Esta nova disciplina, se assim pode-se denominar, transpõe da negação plena do comer, presente nas dietas tradicionais, para uma tentativa de afirmação da dieta, a partir do resgate da dimensão do prazer em comer.

> Palavras-chave: reeducação alimentar, dieta, nutrição, programa de emagrecimento; Internet.
1 Professora adjunta no Departamento Ciências da Nutrição, Escola de Nutrição, Universidade Federal da Bahia. Mestre em Educação dos Profissionais de Saúde, University of Dundee, Escócia. Doutora em Ciências Sociais, PUC-SP. Endereço eletrônico: amparo@ufba.br.

Recebido em: 22/10/2009 Aprovado em: 13/04/2010. 


\section{Considerações iniciais}

Este texto é parte de um estudo sobre estratégias educativas utilizadas pelos programas de emagrecimento oferecidos via Internet e tem o objetivo de discutir alguns aspectos sobre a disciplina alimentar contemporânea. Parte da premissa da visibilidade que o corpo toma no mundo contemporâneo, particularmente na sua concepção como algo em permanente construção, no qual o parâmetro do corpo belo-magro-jovem é a referência. Para tanto, estratégias são desenvolvidas, de forma concomitante e conjugadas, e com suas peculiaridades, com o objetivo de alcançar um corpo idealizado. Dentre elas, destaca-se a dieta, combinada com a atividade física, que conformam os pilares fundamentais para esta construção do corpo (não desconsiderando, evidentemente, o crescente papel das cirurgias plásticas, como também do uso de cosméticos e medicamentos). Tais estratégias são fortemente consubstanciadas por um aparato técnico-científico, o que marca significativamente as formas de lidar com o corpo contemporâneo (SANTOS, 2008).

\section{O percurso metodológico}

Tratou-se de um estudo exploratório cuja primeira etapa foi explorar um site de busca, utilizando como palavra-chave o termo "dieta". O site de busca escolhido foi o "Yahoo.com.br", por ser considerado um dos sites mais explorados pelos internautas no período estudado. Na primeira busca, realizada no período de 8 a 11 de julho de 2003, foram localizados 336 sites cadastrados e 74.800 sites relacionados, englobando uma grande variação de abordagem da temática.

O estudo se concentrou nos 336 sites cadastrados, selecionando-se aqueles que estavam relacionados com os programas de emagrecimento comercializados no Brasil. Dentre eles, foram escolhidos seis sites utilizando-se o critério de popularidade no contexto nacional, além da abrangência das temáticas exploradas pelos programas. Os sites também foram acompanhados semanalmente durante dois meses, para verificar as permanências e as dinâmicas dos fluxos de informaçôes e conteúdos dos programas.

Foi realizada análise dos conteúdos veiculados do material selecionado: o primeiro momento envolveu uma leitura exploratória do material; em seguida, desenvolveu-se um processo de categorização dos temas relevantes para análise, realizando-se ainda uma triangulação de dados. 
A “dieta” estava presente nas mais variadas temáticas e propósitos que iam desde as tradicionais - dieta da lua, dieta das proteínas -, oferta de produtos para o emagrecimento - refeições prontas, medicamentos, aparelhos esportivos, receitas light, informações sobre patologias e sua relação com dieta; como também críticas às dietas rigorosas, como as realizadas pela Associação de Estudos para a Obesidade (ABESO), e sites que resistem à estética da magreza, como a Associação Brasileira dos Gordinhos, e outros que se conformam como um movimento de proteção do direito ao sabor, como o Slow Food. Deste vasto universo, foram selecionados sites que fornecem programas de emagrecimento, considerados os mais populares, a saber: CyberDiet, Emagrecendo, Perca Gordura, Sempre em Forma, Good Light e Dieta Diet.

Uma parte do estudo destinou-se a descrever e analisar alguns elementos estruturantes desses sites (SANTOS, 2007). Partindo da análise dos discursos apresentados nesses programas, o texto reflete primeiramente sobre a transição do conceito de fazer dieta para o conceito de reeducação alimentar, destacando algumas estratégias utilizadas pelos programas. Em seguida, nesta construção de uma nova disciplina alimentar, discute-se sobre a ressignificação do comer e da comida.

\section{Uma nova disciplina alimentar?}

Nos sites estudados, transparece uma possibilidade de corte que contrapóe o conceito do fazer dieta e o conceito de reeducação alimentar. Este último entra no cenário das práticas educativas em alimentação e nutrição nos anos 1990, juntamente com outros termos menos populares, como reabilitação alimentar e aconselhamento alimentar. Também foi encontrado um site com estratégias de reprogramação mental para emagrecer. A mensagem da Associação Brasileira para o Estudo da Obesidade (ABESO) é clara neste sentido: "Diga não às dietas e sim à reeducação alimentar”.

Quando você entra em regime alimentar, há sempre a implicação de que, cedo ou tarde, irá terminá-lo. Se você fizer isso, pode ter certeza que sua gordura vai voltar, e geralmente uns quilinhos a mais de bônus. É claro que regimes são extremamente chatos e não se adequam ao dia-a-dia. Ao invés de tentar um regime severo e chato por toda a vida, que tal mudar seus hábitos alimentares e dar início a Reeducação Alimentar?

[...] as imprudentes dietas ditadas pela moda falham quase sempre. Por isso, emagrecer de uma maneira natural é a melhor e mais segura alternativa hoje. Desde as dietas de elevado teor de proteínas, as de baixo teor de gorduras, das dietas das fibras ou de um só alimento até combinações estranhas e refeições de leite batido. As pessoas que 
querem perder peso seguem uma multiplicidade de conselhos confusos. $\mathrm{Na}$ maior parte dos casos esses conselhos são inofensivos - muitos são tão impraticáveis ou antisociais que ninguém consegue segui-los por muito tempo -, mas, em alguns casos, podem ser perigosos para a saúde ou até levar a pessoa a aumentar o peso. Felizmente, emagrecer não implica seguir as dietas da moda ou padrões absurdos de alimentação. Com uma alimentação equilibrada de alimentos naturais, pobres em gorduras e açúcar, a maior parte das pessoas consegue perder peso com segurança e de maneira simples, estabelecendo padrôes saudáveis de alimentação para a vida inteira. Nos casos de algumas pessoas, a mudança para uma alimentação de baixo teor de gorduras e açúcar obriga apenas a pequenos ajustes em seus hábitos alimentares. Para outras, significa uma mudança radical permanente. Pode ser necessário algum tempo para que a pessoa se habitue às mudanças, mas os efeitos em termos de saúde, o aumento de vitalidade e a perda de peso constituem um poderoso incentivo para insistir, mesmo que ocorram deslizes ocasionais.

Nossa intenção é lhe convencer de que para emagrecer você deve mudar seus hábitos alimentares através da reeducação e esquecer a palavra DIETA [...].

Os trechos acima indicam uma mudança no conceito de emagrecimento, tecendo críticas às dietas rígidas, destacando sua monotonia e as dificuldades em serem seguidas. A noção de finitude no ato de fazer dieta expressa uma suspensão do tempo que difere profundamente das mudanças permanentes a serem incorporadas para toda a vida propostas pela reeducação alimentar.

A principal mensagem da reeducação alimentar veiculada pelos sites é emagrecer, de uma forma saudável, equilibrada e natural, através da adoção de novos hábitos alimentares. Estes novos hábitos alimentares preconizam uma dieta balanceada e equilibrada, em que se pode comer de tudo, sem privaçôes e sacrifícios, com prazer, sem se privar da vida social. Para tanto, é necessário educar os desejos, a ansiedade e a compulsão para comer. Portanto, trata-se de um aprendizado permanente. Assim, o indivíduo poderá emagrecer e manter-se magro, melhorando a sua autoestima, com a promessa de alcançar a felicidade e o prazer em viver entrando em harmonia com o seu corpo.

O confronto com a rigidez da dieta parece ainda trazer marcas do imaginário mecanicista que, como ressalta Sant'anna (2001), é excessivamente monótono, repetitivo e pouco criativo, e toma o lugar a flexibilidade. Nesta última, os "deslizes" (termo frequentemente utilizado em diferentes sites) são vistos como normais e até certo ponto permitidos. É proposto que se um "deslize" for cometido em um dia possa ser compensado no dia posterior. Os programas estimulam aos seus usuários a registrarem o consumo diário ainda que se tenha "exagerado". Tal registro pode 
ainda pode significar a sua possível liberdade de "confessar" sem o temor das repreensões e culpabilização, aspecto que é marcante nas conduções da dieta.

O “depende de você” reforça (ou até amplia) a responsabilização do indivíduo. Ele é convocado para participar da construção cotidiana da sua dieta, ampliando seu poder de decisão, diferente das "dietas prontas e rígidas". O papel do agente é maior no processo, além da possibilidade "comer de tudo" e "sem passar fome", que indica o "fazer escolhas" a todo o momento.

Estes aspectos coadunam com a afirmação de Sant’anna (2001), que ressalta a valorização do espírito de iniciativa no mundo contemporâneo, abandonando os "sistemas hierárquicos fordistas em favor das estruturas leves e pouco autoritárias". No entanto, esta "nova leveza", complementa a autora, pode aumentar a insegurança material e psicológica dos trabalhadores, assim como a ansiedade. Ressalta ainda que "quando a norma não é mais fundada sobre a disciplina e a culpa, e sim sobre a responsabilidade e a iniciativa, aqueles que não conseguem ser responsáveis e ter iniciativa são considerados insuficientes” (p. 26).

Observa-se que a centralidade da reeducação alimentar nos programas estudados esta menos na dieta em si do que nas mudanças no comportamento alimentar, especialmente no controle do apetite. Este é um dos principais pontos diferenciais, pois, observando a composição das dietas, elas não diferem em si em linhas gerais, quanto aos princípios nutricionais vigentes. A centralidade nas dietas de baixa caloria e baixo teor de gordura, especialmente nas gorduras saturadas e no colesterol estão mantidas. Os alimentos funcionais e a fitoterapia têm sido incorporados como estratégias alimentares de apoio na prevenção de doenças e auxílio no emagrecimento.

Dentre as estratégias identificadas no programa, observou-se que as mesmas combinam três elementos fundamentais: o estímulo e motivação com um forte apoio psicológico e de marketing; promessa de não abrir mão do prazer; e o como controlar o apetite. Evidentemente, a promoção de um conjunto de outros elementos também se faz presente, e o principal deles é a atividade física.

\section{A motivação e o estímulo}

A reeducação alimentar parece substituir a forma de "controle-repressão" que marca as dietas tradicionais para a forma de "controle-estímulo", utilizando os termos de Michel Foucault (1979). A base é a responsabilização dos indivíduos e o seu poder 
de iniciativa. Desta forma, os sites utilizam matérias e reportagens que centram no estímulo e nos ganhos que se pode obter com os resultados. Mensagens como "melhore a sua autoestima", "sinta-se feliz com o seu corpo" ou "sinta-se saudável" são títulos, temas e expressões bastante frequentes, trazendo uma ideia de retorno à natureza, leveza, movimento, harmonia interior e equilíbrio.

Há mensagens mais incisivas, tais como "pare de se lamentar e entre em forma!" ou "querer é poder, melhore a sua vida", ou ainda aquelas que centram na recompensa: "comemore os seus sucessos. Que tal se dar um presente a cada quilo perdido?". Os depoimentos também expressam ideias como "força de vontade e disciplina prevaleceram". A questão da autoestima é um tema recorrente e gerador de outras vantagens estimulantes, como a ampliação da amizade, maior credibilidade e ascensão profissional. Ou seja, a partir da construção de uma dieta saudável, que pode resultar em um corpo magro, abre-se a porta para vários outros aspectos: primeiro, o estar bem consigo mesmo e, em seguida, estar bem com outros: amigos, profissão, etc. É a busca da felicidade, através de uma reconstrução do seu ser, estar e agir no mundo. É então através do corpo, como ressalta Mira (2001), que os sucessos e os fracassos são negociados. A autora entende o corpo como o espaço privilegiado para a negociação das diferentes identidades - logo, a recuperação da autoestima é, antes de mais nada, recuperar o próprio corpo.

\section{“...Comer de tudo..."}

A expressão veiculada "comer de tudo" parece ter um estreito vínculo com a incorporação do prazer na disciplina alimentar. O prazer em comer ao longo da história das ciências da nutrição, que sempre teve seu lugar subestimado em prol do "nutritivo" (LEVENSTEIN, 2003), redefine sua posição nesse espaço, tendo contribuição importante com o crescimento da área da gastronomia.

Observou-se que inúmeras receitas e dicas culinárias são oferecidas utilizando uma diversidade de produtos alimentares cuja palavra de ordem é ser light. $\mathrm{O}$ termo light, ressalta Freitas (2002), na sociedade atual significa um modo de vida leve e saudável que também pode ser reinterpretado como "o sentido da leveza da mesa, dos alimentos, do corpo e da vida.” (p. 24). Destaca ainda que desta leveza se decifra o mundo light e clean vinculado à ideia de um corpo magro e limpo, que adjetivam um novo corpo combinando com a forma leve e iluminada. 
Uma receita light, leve em suas cores e textura, marcando uma festividade e alegria, prática em preparar, em que pesem o exotismo e a diferença, inovação e criatividade na busca de novos sabores. E é a gastronomia que tem trazido esses elementos para este novo comer.

No entanto, essa aliança entre as ciências nutricionais e a gastronomia indica que a primeira parece incorporar a gastronomia exercendo sobre ela uma espécie de controle e vigilância. As receitas tradicionais prazerosas indicadas passam por uma reformulação na composição dos produtos, utilizando os de baixa caloria ou propondo mudanças de alguns - como, por exemplo, os cremes de leite são trocados por iogurte desnatado - como também uma nova forma de preparar mais light - no lugar de fritar, grelhar. Em suma, tudo é permitido, desde que se consuma controladamente, como também reelaborado dentro dos parâmetros da "filosofia light":

Não se prive do prazer de devorar uma barra de chocolate (pequena!) de vez em quando. Mas tente alterar sua rotina para encontrar outras fontes de prazer (além do chocolate) na vida. Vale lembrar outra vantagem de não ceder ao chocolate: o gosto fica minutos na língua e as gordurinhas semanas no corpo. Além disso, é um prazer efêmero: basta tomar um copo de água para que ele desapareça do paladar.

Esse exemplo demonstra um controle sobre este prazer alimentar e, até certo ponto busca, através de uma análise racionalizante, descaracterizá-lo e reduzir seu valor para o sujeito. Todavia, esquece-se aqui das estreitas relaçóes entre a memória e a comida, que pode funcionar como um resgate dos momentos vividos outrora. A comida, como mostra Marcel Proust (1995), pode também trazer à tona sua própria história. Logo, o prazer alimentar não pode ser reduzido a um prazer efêmero, reduzindo assim sua complexidade.

Em síntese, este prazer reelaborado e disciplinado parece estar também racionalizado pelas ciências nutricionais, buscando contribuir assim para uma melhor efetivação dos resultados: emagrecer sem sofrer, ou melhor, com prazer. Ele promove uma nova construção do gosto, o gosto light, como ainda deslocá-lo para os resultados de uma dieta: "prazer é perder peso, prazer não é comer bobagem!”.

\section{“...Sem passar fome”}

$\mathrm{Na}$ expressão "não passar fome” está em jogo o controle do apetite. Este se traduz em um dos maiores desafios. A relação "ter apetite" como saudável não faz parte do mundo contemporâneo como outrora. Um indicador desta questão pode ser 
expresso pela redução dos anúncios publicitários dos estimuladores de apetite frente ao significativo aumento dos moderadores. $\mathrm{O}$ controle do apetite e dos desejos alimentares se concebe em um desafio tão importante que os sites estão repletos de textos, matérias e artigos no campo da psicologia, voltados para o autocontrole, determinação e disciplina. A presença de profissionais psicólogos, psiquiatras, como também do campo das práticas alternativas de saúde, forma um campo multidisciplinar na batalha contra a sensação da fome.

Um regime dietético é definido como um sistema de regulação e regras que ditam quais os alimentos devem ser consumidos (LUPTON, 1996). A dieta, vista como necessariamente para a perda de peso ou mesmo para a melhoria da saúde, é uma concepção muito recente na história da humanidade. Giddens (2001) destaca que a invenção da dieta com este propósito ocorre na segunda década do século XX. Todavia, ainda nos tempos atuais, a dieta ainda pode ser vista como uma prática elitizada desenvolvida pelas classes mais altas, associada à restrição e ao sacrifício, tendo a prática alimentar como algo externo ao cotidiano.

Embora, como o autor supracitado afirma, a concepção de dieta vinculada ao emagrecimento e a saúde só emerge na segunda década do século XX; a ideia de controle à mesa se situa alguns séculos atrás. Elias (1994), em seu trabalho sobre o processo civilizador, demonstra os caminhos, a partir do século XVI, pelos quais os indivíduos nas sociedades ocidentais passaram a controlar suas emoções e impulsos, assim como as diferentes funçôes corporais. Um conjunto de regras é internalizado, e a autoconsciência da vergonha, pudor e do constrangimento começava a operar automaticamente.

Elias (1994) ainda destaca como as boas maneiras à mesa foram parte central do processo civilizatório das sociedades ocidentais. Estas foram controlando o corpo, os gestos, de modo que o gradual refinamento à mesa foi associado à repulsão em torno do tocar a comida com as mãos, comer com as mãos e colocar o alimento já mordido de volta a um prato comum, dentre outros processos exemplificados pelo autor, constantes nos manuais da época.

Nesse momento é que Lupton (1996) destaca o início da progressiva "civilização" do apetite. Esta emerge com o aumento da segurança alimentar no século XVIII, combinado com a invenção da culinária - a haute cuisine se desenvolveu na França durante os séculos XVII e XVIII - e as pressóes da corte para diferenciar-se das classes baixas. Enquanto os banquetes representavam 
um sinal de prosperidade e nobreza na Idade Média, no século XVIII começa a aparecer entre a nobreza e classes altas um maior autocontrole sobre o apetite. Os "glutōes" tornaram-se exceçōes entre a nobreza e as classes altas. Pequenos pratos caros e requerendo grande habilidade na preparação tornaram-se a moda da época. Assim, a internalização das práticas de autocontrole e moderação do apetite estava mais relacionada com a preocupação com a aparência, a tentativa de evitar a vulgaridade e se contrapor à natureza animal, do que a preocupação com o corpo e a saúde física, como é interpretada atualmente.

Este parece ser o principal obstáculo para o sucesso desta empreitada em relação às mudanças no comportamento alimentar. Os textos apontam frequentemente a associação apetite e questôes emocionais, destacando a ansiedade e a compulsão:

As causas daquela fome repentina podem ser de fundo físico e/ou emocional. A ansiedade, a preocupação excessiva, a depressão e o estresse são os fatores emocionais que mais levam à alimentação durante o trabalho mesmo que não haja fome.

Estas interpretações são recorrentes, indicando não ser "normal" sentir fome. Há momentos em que a esta se atribui um caráter patológico, como se pode notar na continuidade do texto:

Duas soluções para estes problemas podem ser a prática de esportes e comer sempre nos mesmos horários. Se ainda assim for difícil se livrar do impulso de se alimentar sem que o corpo peça, é aconselhável procurar um bom endocrinologista ou um psiquiatra. Veja mais sobre os Transtornos Alimentares em nossa seção de Compulsão...

Não fica claro no texto quando é que o corpo "pede" para se alimentar, uma vez que a sensação de fome não parece ser uma referência. Designa-se a ciência para definir de forma externa ao sujeito, as necessidades do corpo numa lógica racionalizante, sem dialogar com as sensações corporais. As sensações não são permitidas, devem ser controladas, e caso o sujeito não consiga, este é enquadrado num processo patológico, no qual especialidades como a psiquiatria entram em cena. Os programas também oferecem estratégias para controlar a fome:

Para não se render quando bater a vontade, tome uma água, converse com alguém ou dê uma navegada na Internet. Se você não aguentar, tente comer o que é mais saudável.

Navegar na Internet é uma boa alternativa apontada, pois este mesmo site oferece jogos para os usuários utilizarem quando estão com a sensação de fome, com o intuito de "se distraírem e esquecer" a fome: "sempre que 
bater aquela fome fora de hora que faz você perder o controle, contenha-se brincando com nossos jogos!"

Em suma, as mudanças do comportamento em relação à fome e ao apetite são verdadeiras ações beligerantes que os sujeitos travam com seu interior e os desejos pela comida. Discutem o senso do seu eu, da corporalidade e sua relação com a comida e, quando não são capazes de manter o controle, incompetentes em se conformar aos regimes de emagrecimento, eles experimentam sentimentos de culpa, vergonha, autodesprezo e frustração (LIPOVETSKY, 2000).

\section{A ressignificação do comer e da comida}

Esta nova disciplina alimentar traz, ao lado da ressignificação do comer, a ressignificação dos alimentos e da comida. Vejamos o exemplo dos alimentos ricos em carboidratos, tomando alguns elementos históricos do caso do açúcar.

O açúcar, no auge dos séculos das luzes, representava um alimento totêmico com uma virtude festiva, conforme afirma Roche (1997). Ele representava ainda uma dupla face: de um lado, negra e penosa devido ao trabalho escravo colonial, e de outro, alegre e luminosa, refletindo a nobreza. $\mathrm{O}$ açúcar, presente nos romances, esteve ainda associado à feminilidade, à leveza e à delicadeza. Com a decadência da aristocracia, paralela à ascensão dos valores burgueses, o açúcar desaparece junto à condenação do luxo e ao declínio dos costumes.

Em momento posterior, na segunda metade do século XX, Lupton (1996) lembra do movimento que Claude Fischler (2002) denominou de sacarofobia. O açúcar passa a ser condenado fundamentalmente, devido aos tratamentos tecnológicos associados ao processo de refinamento. $\mathrm{O}$ açúcar muito branco representava um açúcar que passou por um processo de refinamento mais intenso e, por consequência, a utilização de produtos químicos. É também importante lembrar que esta representação parece emergir no bojo da contracultura e o movimento ecológico, com a promoção do retorno à natureza. Os alimentos industrializados passaram por muitas críticas, por agredirem não só a saúde humana, como também a natureza.

O açúcar também começa a ter sua condenação associada à promoção da cárie dental e, por ser um carboidrato, associado também ao aumento de peso. Os carboidratos passaram por seu momento de condenação: pães, massas, pizzas, biscoitos, batata passaram a compor a lista dos alimentos proibidos, que engordam. 
Já no momento mais recente, muito associado à aliança dieta e exercício físico que resultaram em pesquisas fundindo os dois campos, os carboidratos estão sendo reconceituados e são vistos como fonte de energia. No entanto, a concepção anterior ainda está fortemente presente no imaginário social, fato que merece consideração pelos sites:

\begin{abstract}
Medo dos carboidratos: muitas pessoas acreditam que alimentos ricos em carboidratos como batata e pão podem deixá-las mais gordas. Nós armazenamos carboidratos em nossos músculos em forma de energia, e eles só se transformam em gorduras se consumimos em excesso. Consumir baixa quantidade de carboidrato, você simplesmente está reduzindo sua fonte de energia. O ideal é comer dentro do limite diário, e ter energia para gastar se exercitando, e a ginástica ficar menos cansativa.
\end{abstract}

Parece estar presente um acirramento da concepção do corpo-máquina, aumentando sua velocidade, seu metabolismo acelerado. Os carboidratos podem e devem ser consumidos; entretanto, eles precisam ser gastos nos movimentos corporais. Sant’anna (2001, p. 44) ressaltava esta percepção já nos anos 1920:

O organismo humano devia trabalhar cada vez mais rápido, queimar com facilidade os alimentos e transformá-los em energia produtiva. Qualquer semelhança com o motor de combustão não é mera coincidência. As máquinas e os corpos dessa época expressavam a ambição de acelerar suas funçōes [...]

Pode-se também representar, como afirma Crespo (1990), uma acentuação da inversão de valores traduzida na passagem da ideia de acumulação e poupança a preocupaçōes de consumo e dispêndio de energia, que marcaram a passagem do século XVIII para o XIX em Portugal. Por outro lado, a energia tem muitas representações. Ela pode estar associada à energia no conceito da física em si, centrando na transformação da energia química em energia mecânica, como também um conceito mais vinculado com a percepção da energia na sua dimensão espiritual e mística. Alguns alimentos também viram uma espécie de "totem" nessa busca incessante de energia pelo corpo. Um exemplo bem recente no Brasil é o açaí.

O açaí, produto da Amazônia, foi descoberto e disseminado em todo o país, tendo seu consumo vinculado à prática esportiva. $\mathrm{O}$ açaí é um novo símbolo da energia dos praticantes de atividade física que advém de uma região também simbólica como a Amazônia. Natureza e energia se fundem.

Ele também combina com multiculturalismo, a busca da diferença, inovação e criatividade e, com evidência, abertura de novos mercados. Tal representação pode ser enquadrada no princípio da incorporação, denominada por Fischler (2002), 
que trata de um pensamento mágico em que os alimentos absorvidos modificam aquele que come e lhe transmitem suas características. Assim, muitas culturas têm a crença de que a alimentação é o poder privilegiado pela qual se pode exercer o controle de si e sobre os outros.

A permissividade dos carboidratos não engloba todos os tipos. Os carboidratos simples, como o açúcar, continuaram sendo condenados, junto com os doces embora haja a categoria dos doces e chocolates light. Existem inúmeras explicações científicas que pautam esta condenação, mas cabe considerar a entrada no cenário de outros tipos de produtos utilizados para conferir o sabor doce aos alimentos: estamos na era dos adoçantes artificiais.

Sendo também, em sua maioria, produtos químicos, e a não clareza dos efeitos sobre o organismo (estudos indicam sua associação com o câncer, por exemplo), os adoçantes foram inicialmente alvo de críticas, dúvidas e incertezas sobre seu uso. Hoje, com suas dúvidas silenciadas sem se ter resolvido claramente a questão, os adoçantes entraram fortemente no mercado, desbancando de vez o açúcar, sendo hoje seu uso uma regra. Parece que não se concebe uma dieta sem o adoçante. Este se transformou em um símbolo - totêmico talvez - fundamental na decisão do fazer dieta. Parece que é por este caminho que uma dieta começa. As propagandas televisivas exploram excessivamente tal associação.

\section{Uma nova distinção: "açúcar ou adoçante"?}

Ao responder à pergunta “adoçante ou açúcar?”, deixa-se clara sua opção pela vida light ou não. O açúcar, que simbolizava a leveza no Século das Luzes, passa a ter o peso de um hábito tradicional que parece ser tão grotesco quanto consumir gorduras nesta era da lipofobia. Trata-se também de uma distinção, um novo corte diferencial que desloca a linha tênue de separação entre a animalidade e a civilidade. Uma pessoa "distinta” é uma pessoa light, logo ela não consome açúcar e sim adoçante, toma refrigerantes desde que sejam light, ou melhor, devora civilizadamente todos os produtos light à disposição. As regras de etiqueta, tão importantes nos séculos anteriores, normalizando o comportamento externo em relação fundamentalmente ao como comer, hoje parece mais associado ao que se come e o controle do que se come. Promove-se uma reeducação do gosto.

Outro exemplo é o aumento do consumo de frutas e verduras, também amplamente recomendado, que passa por transformaçôes. Tem-se a participação 
dos avanços tecnológicos a serviço da produção, distribuição e processamento dos alimentos, que possibilita o aumento da oferta e variedade das frutas e verduras à disposição, como também a independência dos períodos cíclicos de produção. Esse processo "globaliza" a oferta de frutas. Nunca se viram tantas opções à disposição.

Aqui também há uma nova distinção. Frutas de uma dieta distinta não combinam tanto com as frutas tropicais - banana, laranja -, como também com aquelas que já foram consideradas nobres - pêras e maçãs. Combinam mais com as ameixas frescas, pêssegos que até há pouco tempo, o Brasil só conhecia em suas versões enlatadas.

Brócolis, tomates caquis e berinjelas também são consumidos e repletos de símbolos nessa nova disciplina alimentar. Tal ampliação do consumo tem sido bastante influenciada pela preconização da chamada dieta mediterrânea, que até certo ponto ameaçava as dietas regionais. $\mathrm{O}$ aumento da disponibilidade de gêneros alimentícios coaduna com a construção de uma única dieta considerada saudável. Não parece necessariamente representar uma liberdade de escolha; é uma inovação alimentar vigiada que tem seus imperativos e prerrogativas, que devem ser disciplinadamente respeitados.

\section{Considerações finais}

O momento atual parece estar construindo novas bases que sustentam a disciplina alimentar contemporânea. Esta nova disciplina, se assim podemos denominar, transpõe da negação plena do comer, presente nas dietas tradicionais, para uma tentativa de afirmação da dieta, resgatando a dimensão do prazer em comer e buscando eliminar o sofrimento. A afirmação "perdi o medo da comida" presente em um depoimento, como também "faça as pazes com a comida", em outro site, indicam esta tentativa de reconciliação do homem com a comida.

No entanto, este prazer em comer revelado e prometido pelos programas comporta em suas regras e normas disciplinares uma permissividade e uma racionalização deste prazer ao mesmo tempo em que se busca deslocá-lo para outro campo: o prazer de ser magro, que é mais relevante do que o prazer efêmero do comer. Esta possível ruptura também é marcada por algumas permanências. Embora haja uma diversidade de opções de formas de comer, a lipofobia e calorifobia permanecem como o centro nuclear das estratégias. A redução calórica propostas pelos sites para 
cerca de 1.200 calorias diárias representa uma redução de cerca de $40 \%$ em relação às recomendações da Organização Mundial da Saúde.

A reeducação alimentar também tem a característica de ser uma estratégia proposta para todos os indivíduos e não para grupos específicos, embora procurando respeitar suas individualidades. Todos, adultos e crianças, mulheres e homens, ricos e pobres, estão sendo convocados para esta empreitada de emagrecimento dos corpos, construindo, dentre outras coisas, novos padrões alimentares. Tais mensagens estão cada vez mais presentes nas nossas vidas, de tal forma que, embora alguns tenham uma suposta liberdade de escolha, é muito difícil ficar imune a esta proposição.

$\mathrm{O}$ autocontrole alimentar é um dos aspectos centrais nesse processo. Como lembra Lupton (1996, p. 131), o autocontrole é um dos “aspectos mais dominantes ligados à noção de corpo 'saudável' ou 'civilizado'. Comer é geralmente entendido como uma experiência corporal que requer um contínuo exercício de autodisciplina, evitando o comportamento 'animal' e conforme as normas da sociedade". O exemplo do açúcar e do adoçante ilustra esta questão.

Para tanto, receituários, mensagens e manuais de conduta não faltam neste repertório. Parece que todas as situações da vida em que a comida está presente têm uma recomendação ou dica - estratégias para comer em restaurantes e não engordar, estratégias sobre como comer durante o trabalho, na Páscoa, no Natal, nas férias, no Dia da Pizza, tudo, em detalhes, é encontrado: "não faça nada diferente enquanto come (ver TV ou ler jornal)"; "pouse os talheres entre os bocados e mastigue devagar os alimentos"; "use uma lista durante as compras e não faça compras em jejum ou com fome"; "evite dar ou trocar receitas"; "quando pegar um alimento para comer perguntar se é fome ou não" (lembra o famoso tratado de Erasmo, citado por Nobert Elias, que abordava as boas e más maneiras nas cortes europeias a partir do século XVI).

Para concluir, segue uma dessas mensagens que hipnotizam as formas de pensar e agir sobre o corpo:

Não deixe de folhear revistas de moda só por causa daquelas modelos magérrimas. Acostume-se a admirar as cores, a textura dos tecidos e a criatividade dos estilistas em vez de imaginá-las como inimigos. Quando for a praia, use o bom senso: o excesso de roupa só fará chamar a atenção do que um elegante maiô inteiro. Mande apertar as roupas que estejam dois números acima do seu e nunca use uma peça que esteja justa 
demais. Crie uma rotina de beleza: a manicure o cabeleireiro regularmente. Troque o roteiro gastronômico pelo fitness e entre numa academia. Tenha uma companhia para caminhar 3 vezes por semana na praia, além de exercitar-se terá uma pele bonita e bronzeada. Cuide bem do seu corpo, mexa-se, pratique exercício. Compre uma bicicleta e aceite o desafio de pedalar todos os dias. Suba escadas, caminhe, você vai ver a diferença. Descubra que agora você tem disposição para fazer coisas que antes pedia aos outros. Assuma definitivamente o controle de sua vida. A autoestima é um processo de dentro para fora e o mérito é seu.

\section{Referências}

CRESPO, J. A história do corpo. Lisboa: Difel; 1990.

ELIAS, N. O processo civilizador: Uma história dos costumes, v. 1. Rio de Janeiro: Jorge Zahar, 1994.

FISCHLER, C. O modelo alimentar mediterrâneo: mito e/ou realidade. Projeto História, São Paulo, 2002.

FOUCAULT, M. Microfísica do poder. Rio de Janeiro: Graal; 1979.

FREITAS, M.C.S. Mulher light: corpo, dieta e repressão. In: FERREIRA, S.L.; NASCIMENTO, E.R. Imagens da mulher contemporânea. Salvador: NEIM/UFBA, 2002. 208p.

GIDDENS, A. Modernidade e identidade pessoal. Lisboa: Celta Editora, 2001.

LEVENSTEIN, H. Revolution at the table: the transformation of the American diet. Berkeley: University of California Press, 2003.

LIPOVETSKY, G. A terceira mulher. Permanência e revolução do feminino. São Paulo: Companhias das Letras, 2000.

LUTPON, D. Food, body and the self. London: Sage Publications, 1996.

MIRA, M.C. O leitor e a banca de revistas. A segmentação da cultura no século XX. São Paulo: Olho d'Água, 2001.

PROUST, M. O tempo recuperado. Em busca do tempo perdido v. 7. Rio de Janeiro: Ediouro, 1995.

ROCHE, D. O pão, o vinho, o sabor. In: ROCHE, D. História das coisas banais, Lisboa: Teorema, 1997. p. 249-280.

SANT’ANNA D.B. Corpos de passagem. São Paulo: Estação Liberdade, 2001.

SANTOS, L.A.S. O Corpo, o comer e a comida: um estudo sobre as práticas corporais e alimentares no mundo contemporâneo. Salvador: EDUFBA, 2008. 330p.

SANTOS, L.A.S. Os programas de emagrecimento na Internet: um estudo exploratório. Physis: Revista de Saúde Coletiva, Rio de Janeiro, v. 17, n. 2, 2007. 
From diet to eating re-education: some notes on the contemporary eating based on weight loss programs on the Internet

The paper aims to reflect on contemporary eating based on a study on educational strategies used by weight-loss programs offered through the Internet, which detect a possible transition from the idea of dieting for the eating re-education. It identifies the main message put forward by the sites is "lose weight in a healthy, balanced and natural way, through the adoption of new eating habits, where you can eat everything without hardship and sacrifice, with pleasure, without deprivation of social life" and that they use the sort of strategies combining three elements: the encouragement and motivation with a strong psychological and marketing, "eat everything" with the promise of not giving up the pleasure and the "no hunger" how to control the appetite. The paper also discusses aspects of the new meaning of eating and food that involves the construction of a new eating distinction. Finally, we remark that the present moment seems to build basis that support the contemporary eating discipline. This new discipline, if we can call it so, crosses the complete denial of food, found in traditional diets, to an attempt to reaffirm diet, by recovering the pleasure of eating.

> Key words: food and nutrition, diet, nutrition, weight loss program; Internet. 